\title{
Recombination Reduction on Lead Halide Perovskite Solar Cells based on Low Temperature Synthesized Hierarchical $\mathrm{TiO}_{2}$ Nanorods
}

\author{
Oscar A. Jaramillo-Quintero, ${ }^{1,2}$ Mauricio Solís de la Fuente, ${ }^{1}$ Rafael S. Sanchez, ${ }^{1}$ \\ Ileana B. Recalde, ${ }^{1}$ Emilio J. Juarez-Perez, ${ }^{1}$ Marina Rincon, ${ }^{2, *}$ and I. Mora-Seróo ${ }^{1, *}$ \\ ${ }^{1}$ Institute of Advanced Materials (INAM), Universitat Jaume I, 12006 Castelló, Spain. \\ 2 Instituto de Energías Renovables, Universidad Nacional Autónoma de México, \\ Apartado Postal 34, Temixco, Mor., México 62580. \\ *Corresponding authors: merg@ier.unam.mx, sero@uji.es
}

\begin{abstract}
Intense research on the electron transport material (ETM) has been pursued to improve the efficiency of perovskite solar cells (PSCs) and decrease their cost. More important, the role of the ETM layer is not fully understood, and research on new device architectures is still needed. Here, we report the use of three-dimensional (3D) $\mathrm{TiO}_{2}$ with hierarchical architecture based on rutile nanorods (NR), as photoanode material for PSCs. The proposed hierarchical nanorod films (HNR) were synthesized by a two-steps low temperature $\left(180{ }^{\circ} \mathrm{C}\right)$ hydrothermal method, and consist of $\mathrm{TiO}_{2}$ nanorods trunks with optimal length of $540 \mathrm{~nm}$ and $\mathrm{TiO}_{2}$ nanobranches with lengths of $45 \mathrm{~nm}$. Different device configurations were fabricated with $\mathrm{TiO}_{2}$ structures (compact layer, NR and $\mathrm{HNR}$ ) and $\mathrm{CH}_{3} \mathrm{NH}_{3} \mathrm{PbI}_{3}$, using different synthetic routes, as active material. The PSCs based on $\mathrm{HNR}-\mathrm{CH}_{3} \mathrm{NH}_{3} \mathrm{PbI}_{3}$ reached the highest power conversion efficiency compared to the PSCs with other $\mathrm{TiO}_{2}$ structures. This result can be mainly ascribed to lower charge recombination as we determine by impedance spectroscopy. Furthermore, we have observed that $\mathrm{CH}_{3} \mathrm{NH}_{3} \mathrm{PbI}_{3}$ perovskite deposited by the two-step route shows higher efficiency, surface coverage and infiltration within the structure of 3D HNR than one-step $\mathrm{CH}_{3} \mathrm{NH}_{3} \mathrm{PbI}_{3-\mathrm{x}} \mathrm{Cl}_{\mathrm{x}}$ perovskite.
\end{abstract}

\section{TOC Figure}

Hierarchical $\mathrm{TiO}_{2}$ Nanorods selective contact for perovskite solar cells has been produced at low-temperature by hydrothermal method presenting reduced recombination.

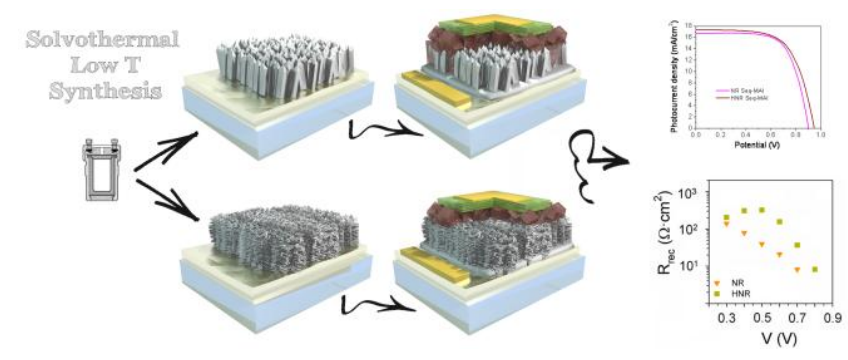




\section{Introduction}

The recent application of organic-inorganic perovskites on solar cells by Kojima et $a l .{ }^{1}$ has open an attractive field for the easy preparation of solution-based processing solar cells at low temperature $\left(<100{ }^{\circ} \mathrm{C}\right)$ for the development of suitable alternatives for energy conversion. ${ }^{2-5}$ Moreover, due to the excellent optoelectronic properties and long diffusion length of electrons and holes, hybrid organic-inorganic lead halide perovskite materials have emerged as light harvesters for solar cells. ${ }^{6-10}$ In the last few years, solution-processed hybrid perovskite solar cells (PSCs) have increased the reported efficiencies from $3.8 \%$ to a certified power conversion efficiency of $20.1 \%$. $^{11}$

The most commonly reported PSC structure consists of a perovskite layer deposited on a compact $\mathrm{TiO}_{2}$ layer with an additional mesoporous layer of $\mathrm{TiO}_{2}$. The mesoporous layer has been systematically used on dye sensitized solar cells (DSCs) and it is proposed to promote a large surface area and good loading of the absorber. ${ }^{12,13}$ However, its role on PSC is still under debate, pointing to imposing some nucleation dynamics of perovskite growth, ${ }^{14}$ helping in obtaining continuous perovskite layers and influencing the selective properties of the electron transporting material (ETM). ${ }^{15}$ Nevertheless, the existence of numerous boundaries among the nanoparticles of the porous layer increases the density of trapping sites and the probability for electron recombination. One-dimensional (1D) $\mathrm{TiO}_{2}$ nanostructures (nanowires, nanotubes or nanorods) have been demonstrated to provide a lower charge recombination rate at the grain boundaries and a superior pathway along the long axis of 1D nanostructures for electron transport in DSCs. ${ }^{16-19}$ Recently, substantial efforts were drawn towards the fabrication of novel three-dimensional (3D) hierarchical architecture ${ }^{20-23}$ with high surface area, fast electron transport and higher nucleation sites for the deposition of perovskite. 3D hierarchical assemblies have been prepared by chemical vapor deposition, ${ }^{21}$ pulsed-laser deposition ${ }^{22}$ and multistage electrospinning and hydrothermal methods. ${ }^{23}$ Wang et $a l .{ }^{21}$ realized $3 \mathrm{D} \mathrm{TiO}_{2}$ nanostructures by surface-reaction-limited pulsed chemical vapor deposition (SPCVD) with superior photovoltaic performance compared to nanowires and nanoparticle systems owing to large surface area and charge transport properties. Unfortunately, this method needs a temperature of $600{ }^{\circ} \mathrm{C}$ during the entire growth process, even higher than those methods used to fabricate compact or nanostructured $\mathrm{TiO}_{2}$ layers, where a high sintering temperature $\left(\sim 500{ }^{\circ} \mathrm{C}\right)$ is usually required to crystallize the as-deposited amorphous films. It has been also reported a positive influence of the use of $\mathrm{TiO}_{2} \mathrm{NRs}$ in the stability of perovskite solar modules. ${ }^{24}$

In this paper, we report a low-temperature synthesized $\mathrm{TiO}_{2}$ nanorods (NRs) and 3D hierarchical nanorods (HNRs) as ETM for PSCs. 3D HNRs were fabricated via twosteps hydrothermal methods leading to PSCs with maximum power conversion efficiency $\left(\mathrm{PCE}_{\max }\right)$ of $10.52 \%$ under $\mathrm{AM} 1.5 \mathrm{G}$ illumination, which was higher than PSCs based on NRs and compact $\mathrm{TiO}_{2}$ films. The good performance of 3D HNR PSC was possible due to the higher light harvesting of NR and HNR structures and to the reduction of recombination losses in HNR respect NR detected by impedance 
spectroscopy. Hence, we developed low-temperature process for ETM layers that give better performance than those using sintering steps, opening its application on PSCs.

\section{Results}

$\mathrm{TiO}_{2}$ NR photoanodes were synthesized directly on the FTO substrates without any template or compact layer (CL), via hydrothermal method, as shown in Fig. 1a,b. Fig. 1 shows the top-view and cross sectional FESEM images of bare $\mathrm{TiO}_{2} \mathrm{NRs}$ with uniform length and width, nearly rectangular cross section and orderly distributed on the entire surface of the FTO substrate. 3D HNRs consist of a NR backbone that branches out into a network of smaller NRs (Fig. 1c,d). For its fabrication, the as prepared $\mathrm{TiO}_{2} \mathrm{NR}$ film was used as seed to grow branched $\mathrm{TiO}_{2}$ NRs by a second-step hydrothermal modification method. Fig. 1c,d demonstrates that each $\mathrm{TiO}_{2} \mathrm{NR}$ is enclosed by $\mathrm{TiO}_{2}$ nanobranches (diameter of $\sim 13 \mathrm{~nm}$ and length of $\sim 45 \mathrm{~nm}$ ). The crystal structures of $\mathrm{TiO}_{2} \mathrm{NR}$ and 3D HNR were both consistent with a tetragonal rutile phase (PDF\#211276), similar to previous results ${ }^{25,26}$ (Fig. S1).
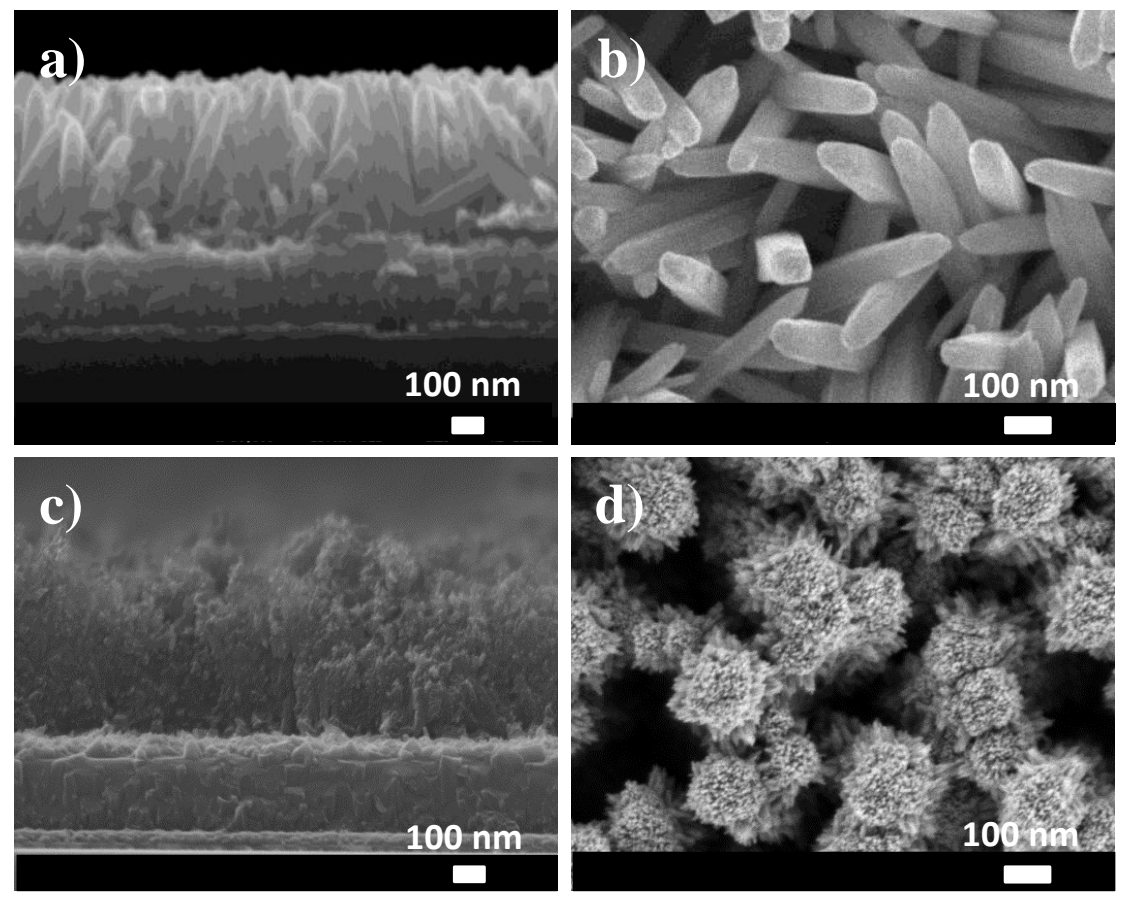

Figure 1.: (a,b) FESEM images of the $\mathrm{TiO}_{2}$ NRs and (c,d) HNRs grown by hydrothermal synthesis. $(\mathrm{a}, \mathrm{c})$ cross-sectional view and $(\mathrm{b}, \mathrm{d})$ top-view.

To fabricate efficient 3D HNR PSCs, preliminary studies were carried out with four different $\mathrm{TiO}_{2}$ NR lengths (from 380 to $1100 \mathrm{~nm}$, controlled by growth time) and different thicknesses of the spin-coated perovskite layer (obtained by varying spin rates). It is worth remarking that all the films were synthesized using similar growth conditions: $180{ }^{\circ} \mathrm{C}$ and $51 \mathrm{~mL}$ of precursor solution and just reaction time was changed (see Experimental Section at Supporting Information). Fig. S2 shows FESEM images of the evolution of NR length as the growth time increases. After keeping the reaction for 110, 120, 125 and $130 \mathrm{~min}$, the lengths of the $\mathrm{TiO}_{2}$ NR were determined to be $\sim 380$, $\sim 540, \sim 700$ and $\sim 1100 \mathrm{~nm}$, respectively, see Fig. S2. 
Devices based on the configuration $\mathrm{FTO} / \mathrm{TiO}_{2} \quad \mathrm{NR} / \mathrm{CH}_{3} \mathrm{NH}_{3} \mathrm{PbI}_{3-\mathrm{x}} \mathrm{Cl}_{\mathrm{x}} /$ SpiroOMeTAD/Au were prepared (Fig 2a). In these devices $\mathrm{CH}_{3} \mathrm{NH}_{3} \mathrm{PbI}_{3-\mathrm{x}} \mathrm{Cl}_{\mathrm{x}}$ was spincoated onto the $\mathrm{TiO}_{2}$ NR through a one-step solution deposition method at different spin rates (from 1000 to 4000 r.p.m.) (see Experimental Section in Supporting Information). Subsequently, a spin-coated Spiro-OMeTAD layer was used as selective contact and hole transport material (HTM). Finally, gold was evaporated onto the Spiro-OMeTAD to form an ohmic contact.

a)

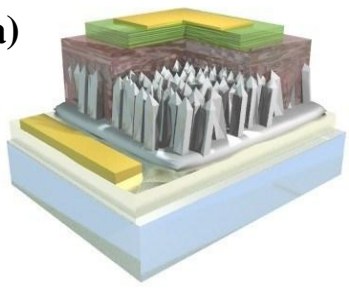

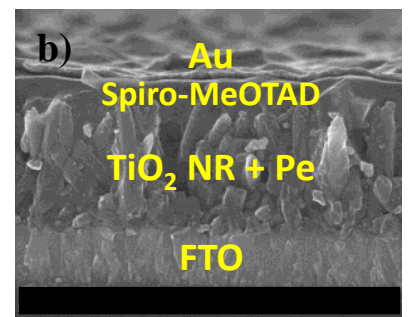

c)

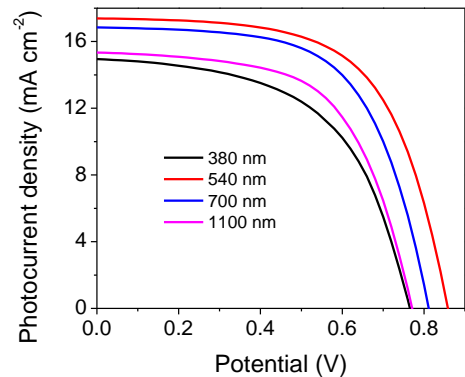

Figure 2.: (a) Device configuration showing the different layers of NR PSC. (b) Cross-section FESEM corresponding to the configuration shown in (a), Good penetration of perovskite in the NR structure can be appreciated. (c) $J / V$ curves of PSC at various nanorod lengths using a spin rate of 2000 r.p.m.

Fig. S3 shows the PCE values of NR PSCs obtained for each $\mathrm{TiO}_{2} \mathrm{NR}$ length with a different thickness of the perovskite layer. It can be observed that, independently of the length, all the NR showed the same optimum spin rate value for the deposition of the perovskite layer, thus obtaining the highest PCE value at 2000 r.p.m.. Higher spin rate causes lower perovskite surface coverage and short circuit between ETM and HTM. The decrease in PCE value when increasing the spin rate is due to the lower amount of deposited perovskite and to the decrease on perovskite surface coverage causing short circuits between ETM and HTM. The best performing current density-voltage $(J / V)$ curves of the NR PSCs under one sun illumination are shown in Fig. 2c as a function of $\mathrm{TiO}_{2}$ NR lengths and the related averaged performance parameters are listed in Table $\mathrm{S} 1$. The average $\mathrm{PCE}$ value $\left(\mathrm{PCE}_{\mathrm{avg}}\right)$ was obtained from the measurement of ten different NR PSCs. $\mathrm{PCE}_{\max }$ of $9.1 \%$ and $\mathrm{PCE}_{\text {avg }}$ of $8.92 \%$ have been obtained for $\mathrm{TiO}_{2}$ $\mathrm{NR}$ length of $540 \mathrm{~nm}$, with short circuit photocurrent density $\left(J_{\mathrm{SC}}\right)=17.49 \mathrm{~mA} \mathrm{~cm}{ }^{-2}$, open-circuit voltage $\left(V_{\mathrm{OC}}\right)=822.63 \mathrm{mV}$ and fill factor $(\mathrm{FF})=0.63$. Furthermore, the photovoltaic parameters were strongly dependent of the $\mathrm{TiO}_{2} \mathrm{NR}$ length. In general, it was found that above $600 \mathrm{~nm}$ NR length, the value of PCE decreases as shown in Fig. $2 \mathrm{c}$ and Table $\mathrm{S} 1$. Previous studies using $1 \mathrm{D} \mathrm{TiO}_{2}$ nanostructures, ${ }^{25,27}$ suggested that this is due to charge recombination at the larger $\mathrm{TiO}_{2} \mathrm{NR}$-perovskite interface. ${ }^{28,29}$

To demonstrate the benefits of using a 3D hierarchical architecture as photoanode, PSCs were fabricated with a compact layer of $\mathrm{TiO}_{2}$ (flat), bare $\mathrm{TiO}_{2} \mathrm{NR}$ and $3 \mathrm{D} \mathrm{HNR}$. For this study, flat device is suited as the control device. 3D HNR films were synthesized, as explained in the experimental section, using the optimum $\mathrm{TiO}_{2} \mathrm{NRs}$ (540 nm length) as seeds. We have also tested the influence of the perovskite growth 
method in the device configuration comparing mixed-halide $\mathrm{CH}_{3} \mathrm{NH}_{3} \mathrm{PbI}_{3-\mathrm{x}} \mathrm{Cl}_{\mathrm{x}}$ perovskite (Sing-MAICl), where a single deposition step is used, and lead iodide $\mathrm{CH}_{3} \mathrm{NH}_{3} \mathrm{PbI}_{3}$ perovskite (Seq-MAI), where two steps are utilized, see Supporting Information for further experimental details. The different PSCs configurations are shown in Fig. 3. Fig. 3a,b,c show the device configuration for Sing-MAICl PSCs, where $\mathrm{CH}_{3} \mathrm{NH}_{3} \mathrm{PbI}_{3-\mathrm{x}} \mathrm{Cl}_{\mathrm{x}}$ was deposited by one-step technique at 2000 r.p.m., as described above. For Seq-MAI PSCs (Fig. 3g,h,i) a two-steps sequential deposition $\operatorname{method}^{5}$ was implemented. Briefly, a $\mathrm{PbI}_{2}$ layer was spin-coated on $\mathrm{TiO}_{2}$ photoanodes, followed by a dipping treatment in a solution of $\mathrm{CH}_{3} \mathrm{NH}_{3}$ I. The same perovskite deposition procedure has been utilized for all three different substrates, with no further optimization analysis at each particular substrate morphology.

Cross sectional FESEM images of FTO/TiO 2 NR (HNRs)/Sing-MAICl (Seq-MAI) were taken to investigate the infiltration of the perovskite within the structures of the $\mathrm{TiO}_{2} \mathrm{NR}$ and 3D HNR (Fig. 3e,f and 3k,1). We can observe the good surface coverage and infiltration of either Sing-MAICl or Seq-MAI perovskite layers within $\mathrm{TiO}_{2} \mathrm{NR}$ and 3D HNR photoanodes. It is important to remark that uniform coverage and adequate infiltration have been observed to be critical factors to obtain excellent photovoltaic parameters in PSCs. ${ }^{30,31}$ Moreover, Fig. S4 shows the top-view FESEM images of the Sing-MAICl and Seq-MAI perovskite layers. Sing-MAICl layer on Flat, NR and HNR is smooth, homogeneous and perfectly covers the $\mathrm{TiO}_{2}$ photoanode as shown in Fig. S4a; whereas, Seq-MAI consists of cuboids (Fig. S4b) with a grain size $\sim 405 \mathrm{~nm}$, in agreement with the value reported for the concentration of $\mathrm{CH}_{3} \mathrm{NH}_{3} \mathrm{I}$ used. ${ }^{32}$ In fact, sequential deposition that produces excellent results for PSCs when $\mathrm{TiO}_{2}$ scaffold is employed, ${ }^{5}$ does not produce good results when perovskite is deposited directly on top of compact $\mathrm{TiO}_{2}$ layer. Large crystal (Fig. S4b) do not cover completely FTO layer, producing the direct contact between selective contacts (compact $\mathrm{TiO}_{2}$ and spiroOMeTAD). 

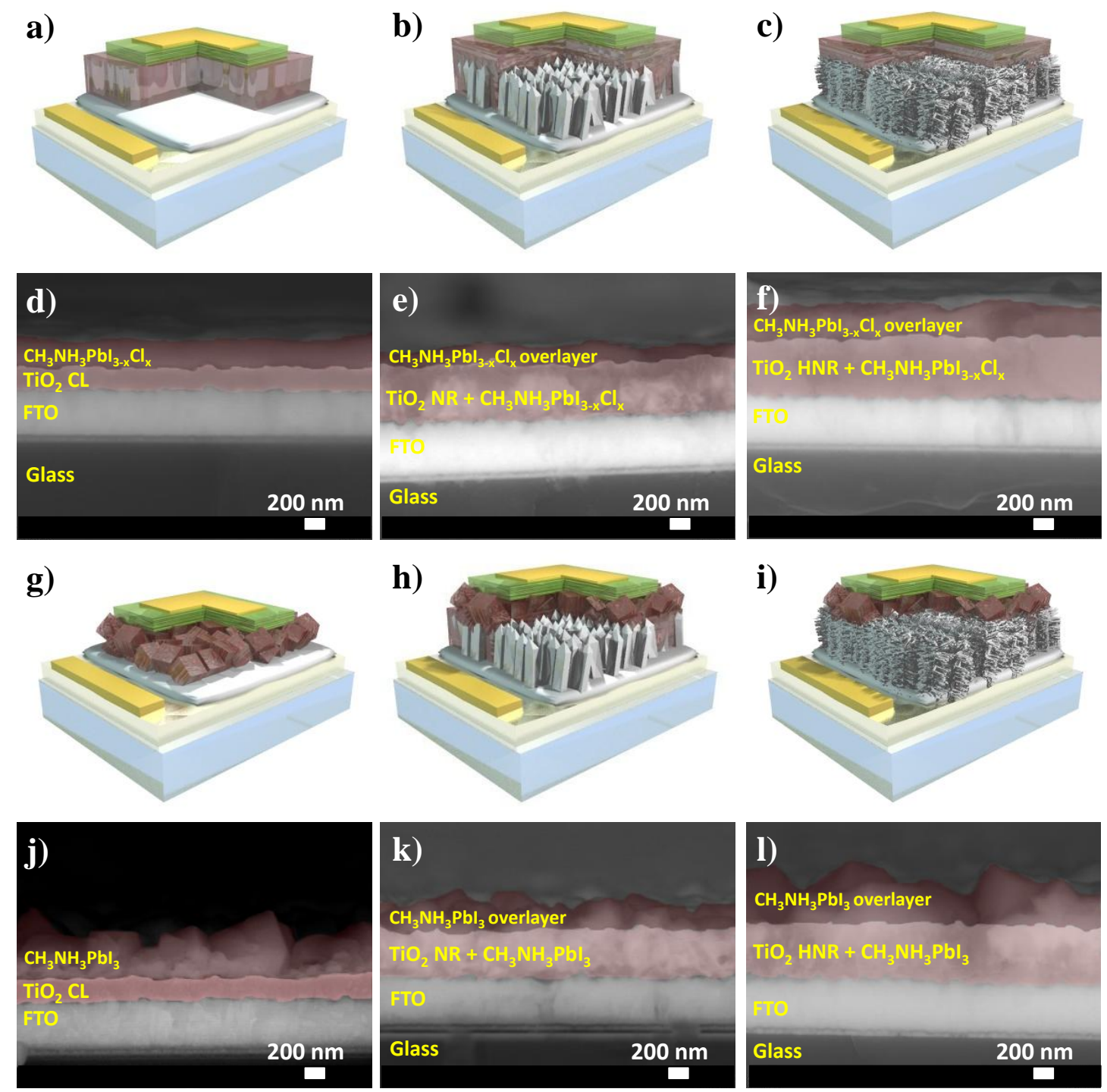

Figure 3: Different device configurations of PSCs and cross-sectional FESEM images of $\mathrm{TiO}_{2}$ and perovskite layers. (a,d) Flat Sing-MAICl. (b,e) NR Sing-MAICl. (c,f) HNR Sing-MAICl. (g,j) Flat SeqMAI. (h,k) NR Seq-MAI and (i,l) HNR Seq-MAI.

The effects of $\mathrm{TiO}_{2}$ morphology on the performance of the PSCs fabricated from Flat, NR and HNR photoanodes were investigated. A summary of the photovoltaic performance and averaged parameters is shown in Fig. 4 and Table 1. NR and HNR present higher $J_{\mathrm{SC}}$ than flat samples, due to a thicker perovskite layer, see Fig. 3. Except for the Sing-MAICl planar architecture, higher values are obtained for devices based on Seq-MAI, mostly because of the higher values on $V_{\text {OC. }}$ The device with HNR Seq-MAI reached a promising maximum PCE of $10.5 \%$ resulting from $J_{\mathrm{SC}}=17.33 \mathrm{~mA} \mathrm{~cm}{ }^{-2}, V_{\mathrm{OC}}$ $=946.96 \mathrm{mV}$ and $\mathrm{FF}=0.64$. Also, HNR Sing-MAICl reports the best PCE $(9.44 \%)$ among the PSCs based on MAICl configuration, indicating that 3D hierarchical architecture is superior to bare NR and Flat films, for the analyzed growth conditions. $^{21,23}$ Comparing NR and HNR samples, the decrement of the incident- 
photon-to-current conversion efficiency (IPCE) above $\sim 480 \mathrm{~nm}$ is more pronounced for PSCs based on NR (Fig. 4c,d) than on HNR, although the Flat device shows the highest decrement in this wavelength range. The integrated short-circuit current density $J_{\mathrm{SC} \text {,INT }}$ calculated from IPCE is consistent with the Jsc values obtained from a solar simulator, see Table 1.

a)

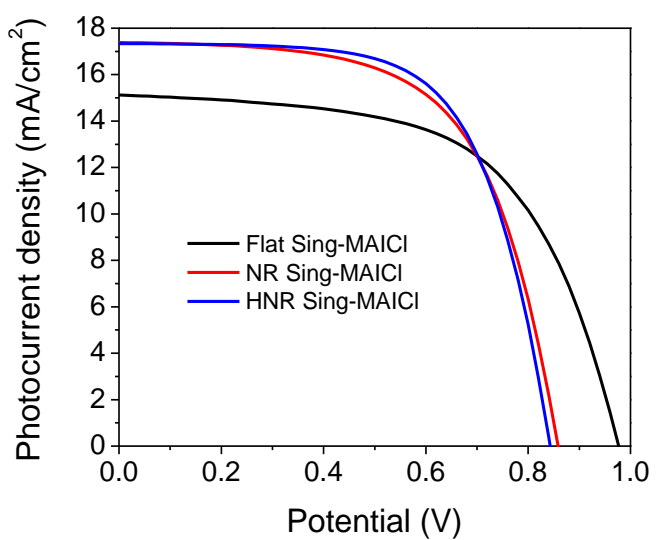

c)

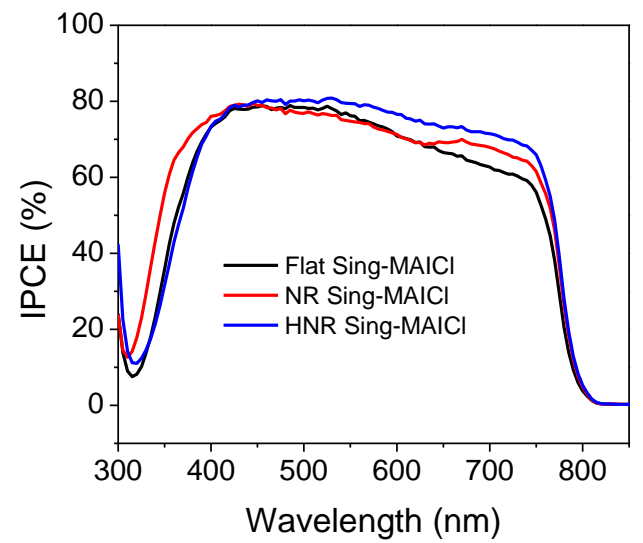

b)

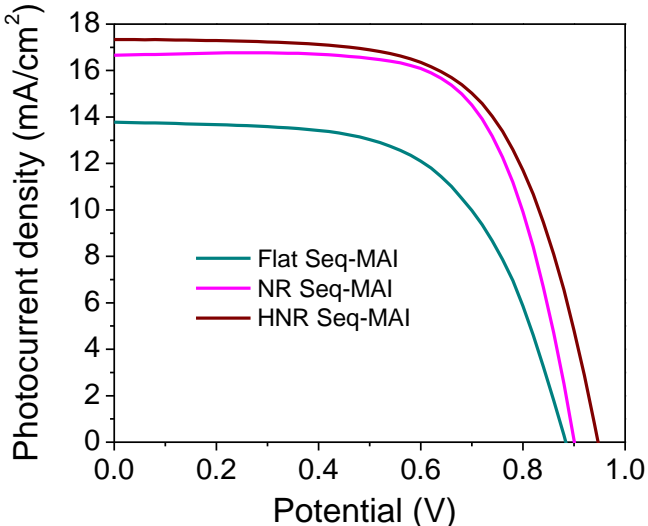

d)

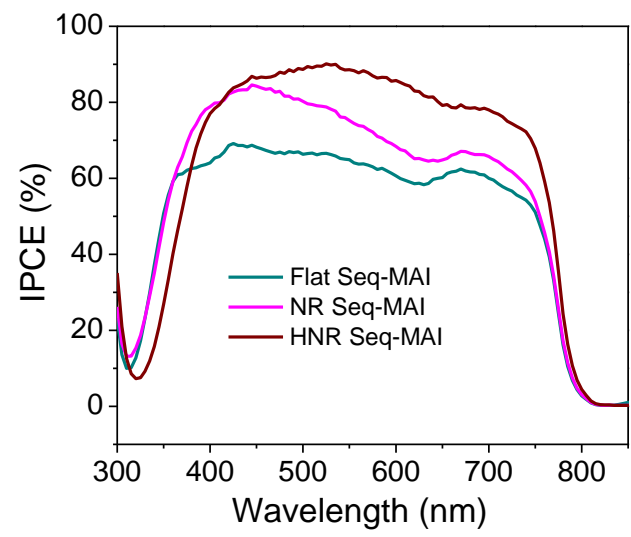

Figure 4.: $J / V$ curves and IPCE spectra of PSC based on different configuration. (a,c) Sing-MAICl. (b,d) Seq-MAI.

Table 1. Average $J / V$ curves parameters and standard deviation based on ten PSCs

with different configuration.

\begin{tabular}{|c|c|c|c|c|c|}
\hline Device configuration & $\mathbf{J}_{\text {sc }}\left(\mathbf{m A} / \mathbf{c m}^{2}\right)$ & $\begin{array}{c}\mathbf{J}_{\text {sc,int }} \\
\left(\mathbf{m A} / \mathbf{c m}^{2}\right)\end{array}$ & $\boldsymbol{V}_{\boldsymbol{o c}}(\mathbf{m V})$ & $\mathbf{F F}(\%)$ & Efficiency (\%) \\
\hline Flat Sing-MAICl & $14.54 \pm 0.62$ & 15.70 & $984.85 \pm 21.11$ & $60.24 \pm 1.19$ & $8.62 \pm 0.40$ \\
\hline NR Sing-MAICl & $16.91 \pm 0.65$ & 16.38 & $832.77 \pm 27.43$ & $62.46 \pm 1.84$ & $8.86 \pm 0.31$ \\
\hline HNR Sing-MAICl & $17.07 \pm 0.83$ & 16.82 & $836.42 \pm 13.02$ & $63.86 \pm 0.77$ & $9.03 \pm 0.42$ \\
\hline Flat Seq-MAI & $14.56 \pm 0.52$ & 14.07 & $885.14 \pm 13.18$ & $54.69 \pm 3.49$ & $7.01 \pm 0.44$ \\
\hline
\end{tabular}




\begin{tabular}{|c|c|c|c|c|c|}
\hline NR Seq-MAI & $16.60 \pm 0.51$ & 15.99 & $898.20 \pm 6.58$ & $65.10 \pm 2.01$ & $9.72 \pm 0.31$ \\
\hline HNR Seq-MAI & $16.97 \pm 0.23$ & 18.11 & $937.99 \pm 10.01$ & $62.83 \pm 1.57$ & $10.06 \pm 0.46$ \\
\hline
\end{tabular}

More interesting is the dependence of $V_{\mathrm{OC}}$ on $\mathrm{TiO}_{2}$ morphology and perovskite type. An increase in $V_{\mathrm{OC}}$ with the use of 3D HNR as photoanode instead of NR or Flat films is in accordance with previous results in the literature. ${ }^{21,23} V_{\mathrm{OC}}$ is strongly influenced by the recombination rate. ${ }^{33}$ In order to study the effect of recombination on the measured devices, impedance spectroscopy under 1 Sun illumination has been carried out. Fig. 5 shows the recombination resistance, $R_{r e c}$, obtained from impedance analysis. ${ }^{34}$ There is a clear correlation between higher $R_{\text {rec }}$ and higher $V_{\mathrm{OC}}$. From Fig. 5a it is observed that for samples using Sing-MAICl, $R_{\text {rec }}$ follows the trend Flat $>\mathrm{HNR}>\mathrm{NR}$ as the $V_{\mathrm{OC}}$ does, see Table 1. Indicating that the recombination rate increases as NR $>$ HNR $>$ Flat. In contrast for Seq-MAI, see Fig. $5 \mathrm{~b}, R_{\text {rec }}$ follows the trend HNR $>$ NR $>$ Flat also in good agreement with the trend observed in the obtained $V_{\mathrm{OC}}$, see Table 1. Taking into account that the recombination rate is inversely proportional to the recombination resistance, ${ }^{33}$ the differences between Flat samples prepared by Sing-MAICl and Seq-MAI can be ascribed to the higher recombination in Flat Seq-MAI due to the non-complete covering of the compact $\mathrm{TiO}_{2}$ surface, See Fig. S4b, as it has been already commented. Moreover, these results also point to a superior performance of HNR in comparison with NR, and also to flat samples in the case of Seq-MAI. We hypothesize that this effect could be ascribed to a lower density of surface traps in 3D HNR, which can lead to a lower net charge recombination at the $\mathrm{TiO}_{2}$-perovskite interface, despite the larger effective surface of HNRs in comparison with NRs.

The superior performance of Seq-MAI in comparison with Sing-MAICl, except for the already analyzed case of Flat Seq-MAI, is also due to the lower recombination rate in Seq-MAI. The lower recombination observed for Seq-MAI in the case of NRs, see Fig. 5c, and in the case of HNRs, see Fig. S5, is the responsible of the higher $V_{\mathrm{OC}}$ observed for these samples, see Table 1. The growth method used for the synthesis of perovskite layer also has an important effect in the device recombination and consequently on the final performance. 

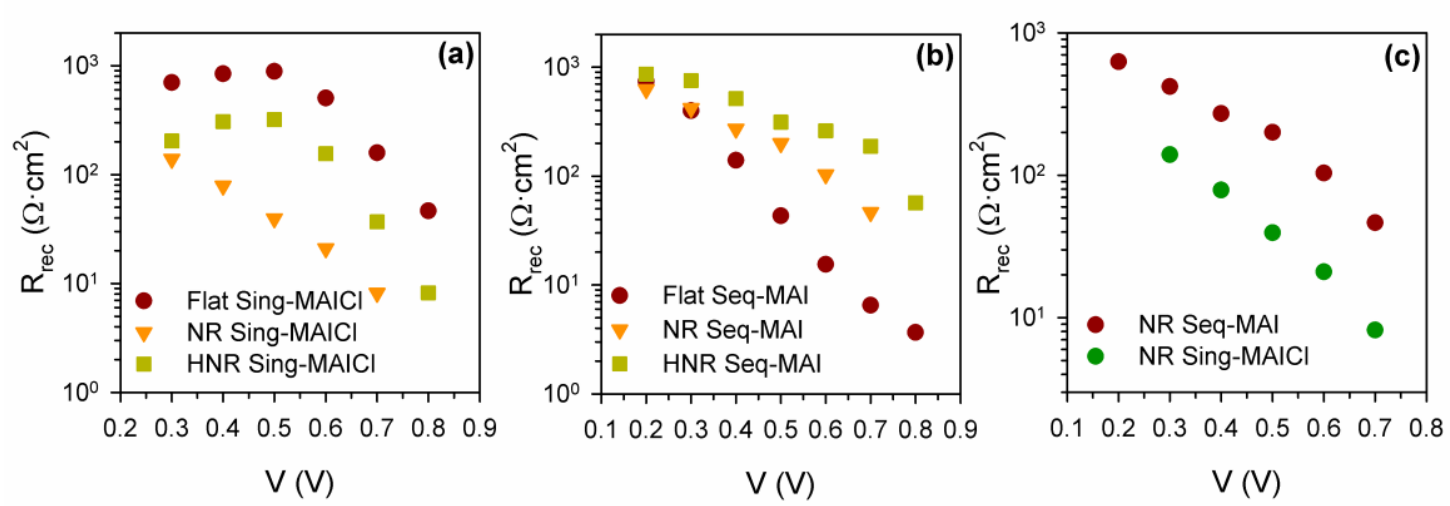

Figure 5.: Recombination resistance $\left(R_{\text {rec }}\right)$ obtained from impedance spectroscopy for samples with (a) Sing-MAICl or (b) Seq-MAI as light harvester. (c) Comparison of $R_{r e c}$ for NR samples using Seq-MAI and Sing-MAICl as light harvester.

\section{Conclusions}

In summary, we have demonstrated an enhanced power conversion efficiency through the use of 3D hierarchical structures based on nanorods with optimized $\mathrm{TiO}_{2}$ NR length and Seq-MAI perovskite layer. The superior efficiency 3D HNR as photoanode is based on one hand on the higher light harvesting properties of NR and HNR in the studied conditions, compared to flat devices. However light harvesting could be increased for flat samples with other growth conditions, but we have preferred to prepared all the samples with the same deposition procedure independently of the substrate in order to avoid introducing additional growth considerations. On the other hand the superior performance of HNR is based on the lower recombination rate obtained from HNR, especially for HNR Seq-MAI, where recombination rate is lower than in NR samples prepared with both depositions and even lower than in flat samples prepared with sequential method. Lower recombination rate causes a significant increase $V_{\mathrm{OC}}$ compared to the other $\mathrm{TiO}_{2}$ structures. Further research is necessary to identify the exact recombination pathway in each configuration and the way in which HNR hinders it, despite the higher surface area. The low temperature hydrothermal routes have the additional advantage of low-cost and the versatility to be implemented in other substrates, including flexible ones. More work is still needed to optimize the use of these low-cost ETM for the preparation of PSCs with record values as those reported in the literature. Nevertheless, the results here reported highlight the importance of the charge selective contacts in the ultimate performance of PSCs and the relationship with the recombination processes. Results also shows that not just material but structure plays an important role in the selective contacts of PSCs. Finally, they show that advanced selective contacts with reduced recombination grown at low temperature are possible, thus paving the way for future flexible opto-electronic applications. 


\section{Acknowledgement}

This work was supported by the Universitat Jaume I (project 12I361.01/1), Spanish MINECO (Project MAT2013-47192-C3-1-R), CONACYT-México (Project CB2010/153270) and UNAM (PAPIIT- IN103015). M.S.F. would like to thank CONACYT México for his postdoctoral grant. O.A.J.-Q. would like to thank CONACYT México for his Ph.D. fellowship.

\section{Reference}

1 A. Kojima, K. Teshima, Y. Shirai and T. Miyasaka, J. Am. Chem. Soc., 2009, 131, 6050-6051.

2 N. J. Jeon, J. H. Noh, W. S. Yang, Y. C. Kim, S. Ryu, J. Seo and S. I. Seok, Nature, 2015, 517, 476-480.

3 H.-S. Kim, I. Mora-Seró, V. González-Pedro, F. Fabregat-Santiago, E. J. JuarezPerez, N.-G. Park, J. Bisquert, Nat. Commun., 2013, 4, 2242.

4 M. M. Lee, J. Teuscher, T. Miyasaka, T. N. Murakami and H. J. Snaith, Science, 2012, 338, 643-647.

5 J. Burschka, N. Pellet, S.-J. Moon, R. Humphry-Baker, P. Gao, M. K. Nazeeruddin and M. Graetzel, Nature, 2013, 499, 316-319.

6 J. H. Noh, S. H. Im, J. H. Heo, T. N.' Mandal and S. I. Seok, Nano Lett., 2013, 13, 1764-1769.

7 L. Bertoluzzi, R. S. Sánchez, L. Liu, J.-W. Lee, E. Mas-Marzá, H. Han, N.-G. Park, I. Mora-Seró, J. Bisquert, Energy Environ. Sci., 2015, 8, 910-915.

8 S. D. Stranks, G. E. Eperon, G. Grancini, C. Menelaou, M. J. P. Alcocer, T. Leijtens, L. M. Herz, A. Petrozza and H. J. Snaith, Science, 2013, 342, 341-344.

9 K. G. Stamplecoskie, J. S. Manser and P. V. Kamat, Energy Environ. Sci., 2015, 8, 208-215.

10 Q. Lin, A. Armin, R. C. R. Nagiri, P. L. Burn and P. Meredith, Nature Photon., 2015, 9, 106-112.

11 W. S. Yang, J. H. Noh, N. J. Jeon, Y. C. Kim, S. Ryu, J. Seo and S. I. Seok, Science, 2015, 348, 1234-1237.

12 M. K. Nazeeruddin, A. Kay, I. Rodicio, R. Humphrybaker, E. Muller, P I iska, N. Vlachopoulos and M. Grätzel, J. Am. Chem. Soc., 1993, 115, 6382-6390.

13 G. J. Meyer, ACS Nano, 2010, 4, 4337-4343.

14 S. T. Williams, C.-C. Chueh and A. K.-Y. Jen, Small, 2015, 11, 1-9.

15 A. Listorti, E.J. Juarez-Perez, C. Frontera, V. Roiati, L. Garcia-Andrade, S. Colella, A. Rizzo, P. Ortiz, and I. Mora-Sero, J. Phys. Chem. Lett. 2015, 6, $1628-1637$

16 Y. Bai, I. Mora-Seró, F. De Angelis, J. Bisquert and P. Wang, Chem. Rev., $2014,114,10095-10130$.

17 J. Tian, Z. Zhao, A. Kumar, R. I. Boughton and H. Liu, Chem. Soc. Rev., 2014, 43, 6920-6937.

18 X. Wang, Z. Li, J. Shi and Y. Yu, Chem. Rev., 2014, 114, 9346-9384.

19 M. C. Beard, J. M. Luther and A. J. Nozik, Nat. Nanotechnol., 2014, 9, 951954.

20 X. Tan, P. Qiang, D. Zhang, X. Cai, S. Tan, P. Liu and W. Mai, CrystEng Comm, 2014, 16, 1020-1025.

21 Y. Yu, J. Li, D. Geng, J. Wang, L. Zhang, T. L. Andrew, M. S. Arnold and X. Wang, ACS Nano, 2015, 9, 564-572.

22 F. Sauvage, F. Di Fonzo, A. Li Bassi, C. S. Casari, V. Russo, G. Divitini, C. Ducati, C. E. Bottani, P. Comte and M. Graetzel, Nano Lett., 2010, 10, 25622567.

23 K. Mahmood, B. S. Swain and A. Amassian, Adv. Mater., 2015, 27, 2859-2865.

24 A. Fakharuddin, F. Di Giacomo, A.L. Palma, F. Matteocci, I. Ahmed, S. Razza, A. D’Epifanio, S. Licoccia, J. Ismail, A. Di Carlo, T.M. Brown, and R. Jose, ACS Nano, 2015, 9, 8420-8429.

25 H. S. Kim, J. W.Lee, N. Yantara, P. P. Boix, S. A. Kulkarni, S. Mhaisalkar, M. Grätzel M, N.-G. Park, Nano Lett., 2013, 13, 2412-2417.

26 J. Qiu, Y. Qiu, K. Yan, M. Zhong, C. Mu, He Yan and S. Yang, Nanoscale, 2013, 5, 3245-3248.

27 R. Salazar,M. Altomare, K. Lee, J. Tripathy, R. Kirchgeorg, N. T. Nguyen, M. Mokhtar, A. Alshehri, S. A. Al-Thabaiti and P. Schmuki, ChemElectroChem, 2015, 2, 824-828. 
28 F. J. Ramos, M. Oliva-Ramirez, M. K. Nazeeruddin, Michael Graetzel, A. R. González-Elipe and S. Ahmad, J. Mater. Chem. A, 2015, 3, 13291-13298.

29 S. Dharani, H. K. Mulmudi, N. Yantara, P. T. Thu Trang, N.-G. Park, M. Graetzel, S. Mhaisalkar, N. Mathews and P. P. Boix, Nanoscale, 2014, 6, 16751679.

30 J. H. Heo, S. H. Im, J. H. Noh, T. N. Mandal, C.-S. Lim, J. A. Chang, Y. H. Lee, H.-J. Kim, A. Sarkar, Md. K. Nazeeruddin, M. Graetzel and S. I. Seok, Nature Photon., 2013, 7, 486-491.

31 T. Leijtens, B. Lauber, G. E. Eperon, S. D. Stranks and H. J. Snaith, J. Phys. Chem. Lett. 2014, 5, 1096-1102.

32 H. S. Kim and N.-G. Park, J. Phys. Chem. Lett., 2014, 5, 2927-2934.

33 F. Fabregat-Santiago, G. Garcia-Belmonte, I. Mora-Sero and J. Bisquert, Phys. Chem. Chem. Phys., 2011, 13, 9083-9118.

34 E.J. Juarez-Perez, M. Wußler, F. Fabregat-Santiago, K. Lakus-Wollny, E. Mankel, T. Mayer, W. Jaegermann, and I. Mora-Sero, J. Phys. Chem. Lett., $2014,680-685$. 